PERSPECTIVE

\title{
Protein kinase $C$ inhibition and diabetic retinopathy: a shot in the dark at translational research
}

\author{
R Donnelly, I Idris, J V Forrester
}

\section{Translational research in practice: a PKC- $\beta$ inhibitor for diabetic retinopathy}

See end of article for authors' affiliations

......................

Correspondence to: Professor Richard Donnelly, Division of Vascular Medicine, University of Nottingham, Derbyshire Royal Infirmary, Derby DEl 2QY, UK: Richard.donnelly@ nottingham.ac.uk

Accepted for publication 26 June 2003
$\mathrm{R}$ educing the incidence and slowing the progression of diabetes related microvascular complications remains a difficult challenge. In the case of diabetic retinopathy, tight glucose and blood pressure control are difficult to achieve and maintain in practice, yet still only provide partial protection against sight threatening complications in the lifetime of a person with diabetes. ${ }^{1}$ More than 250000 patients every year develop sight threatening diabetic retinopathy in the United States alone, ${ }^{2}$ often despite good compliance with antidiabetic and antihypertensive treatments. Furthermore, the morbidity and healthcare costs associated with diabetic retinopathy are likely to escalate as the prevalence of type 2 diabetes increases and as patients with diabetes live longer. For example, the effectiveness of cholesterol lowering drugs and angiotensin converting enzyme (ACE) inhibitors in preventing macrovascular (mostly coronary heart disease) deaths, as well as the wider use of renal replacement therapy, means that patients with diabetes related complications are more likely to survive to experience the distress of failing visual acuity as a result of retinopathy. Thus, as well as improving systems for eye screening and detection of retinopathy, new therapeutic strategies are urgently needed as an adjunct to existing treatments-glucose and blood pressure reduction, photocoagulation and vitreous surgical techniques-to improve visual outcomes for patients with diabetes.

\section{ROLE OF PROTEIN KINASE C ACTIVATION IN HYPERGLYCAEMIA INDUCED RETINAL INJURY}

Several biochemical mechanisms have been identified in the pathogenesis of hyperglycaemia induced vascular damage, but increased de novo synthesis of diacylglycerol (DAG), the endogenous activator of protein kinase C (PKC), is especially important in mediating a variety of unwanted functional and structural abnormalities in vascular tissues (fig 1). ${ }^{3}$ Adding and removing $\mathrm{PO}_{4}$ groups to intracellular proteins, via kinases and phosphatases respectively, is an important regulatory system for activating and deactivating tissue enzymes, receptor pathways, and transcription factors controlling gene expression. PKC mediated phosphorylation of numerous substrate proteins at serine or threonine
Br J Ophthalmol 2004;88:145-151

residues triggers a cascade of pathophysiological responses. $^{4}$ In diabetic retinopathy, PKC mediated changes in endothelial permeability, ${ }^{5}$ blood flow, ${ }^{6}$ and both the formation and response to angiogenic growth factors ${ }^{7}$ contribute to retinal leakage, ischaemia, and neovascularisation (fig 1). PKC activation also contributes to loss of capillary pericytes, ${ }^{8}$ an early feature of diabetic retinopathy. In addition, because of cross-talk between different signalling pathways, hyperglycaemia induced PKC activation augments biochemical responses triggered by other pathophysiological mechanismsfor example, hypoxia,' shear stress and raised capillary pressure, and/or increased activity of the local renin-angiotensin system. ${ }^{10}$

$\mathrm{PKC}$ is not a single enzyme, but rather a family of structurally and functionally related proteins (isoenzymes) derived from multiple genes (at least three) and from alternative splicing of single mRNA transcripts. ${ }^{11}$ Twelve isoforms of PKC have been cloned and characterised according to structure and cofactor requirements (table 1): (1) group A (classic) PKCs, cPKC- $\alpha$, $\beta_{\mathrm{I}}, \beta_{\mathrm{II}}$, and $\gamma$ require phospholipid and calcium for activation; (2) group B (novel) PKCs, nPKC$\delta, \epsilon, \eta, \theta$, and $\mu$ require phospholipid but are calcium independent; and (3) group C (atypical) PKCs, aPKC- $1, \lambda$, and $\xi$ require neither calcium nor phospholipid. Individual isoforms have different patterns of tissue expression, reflecting complex multifunctional roles in phosphoregulation. ${ }^{12}$

Increased tissue content of diacylglycerols, especially palmitate rich DAG, have been reported in vascular endothelial and smooth muscle cells cultured in high glucose conditions and in various cardiovascular tissues from diabetic animals-for example, retina, aorta, heart, and glomeruli. ${ }^{3}{ }^{13} 14$ A group at the Joslin Diabetes Centre first observed that different PKC isoforms are differentially responsive to hyperglycaemia. ${ }^{15}$ It seems likely that different species of DAG (varying in fatty acid composition) selectively activate one or more PKC isoforms in different tissues. Evidence emerged that hyperglycaemia induced DAG (rich in palmitate) activates several PKC isoforms in vascular, retinal, and renal tissues, but quantitatively there was a greater increase in activity of PKC- $\beta_{\text {I }}$ and $\beta_{\text {II }}$ relative to other PKCs. ${ }^{15}$ Other isozymes activated by hyperglycaemia, albeit to a lesser extent, include PKC- $\alpha, \gamma$, and $\delta .^{3}$ In addition, glucose appears to regulate proliferative responses in retinal endothelial cells via the atypical PKC isozyme, PKC-1. ${ }^{16}$ In humans, PKC activity in circulating monocytes correlates with 


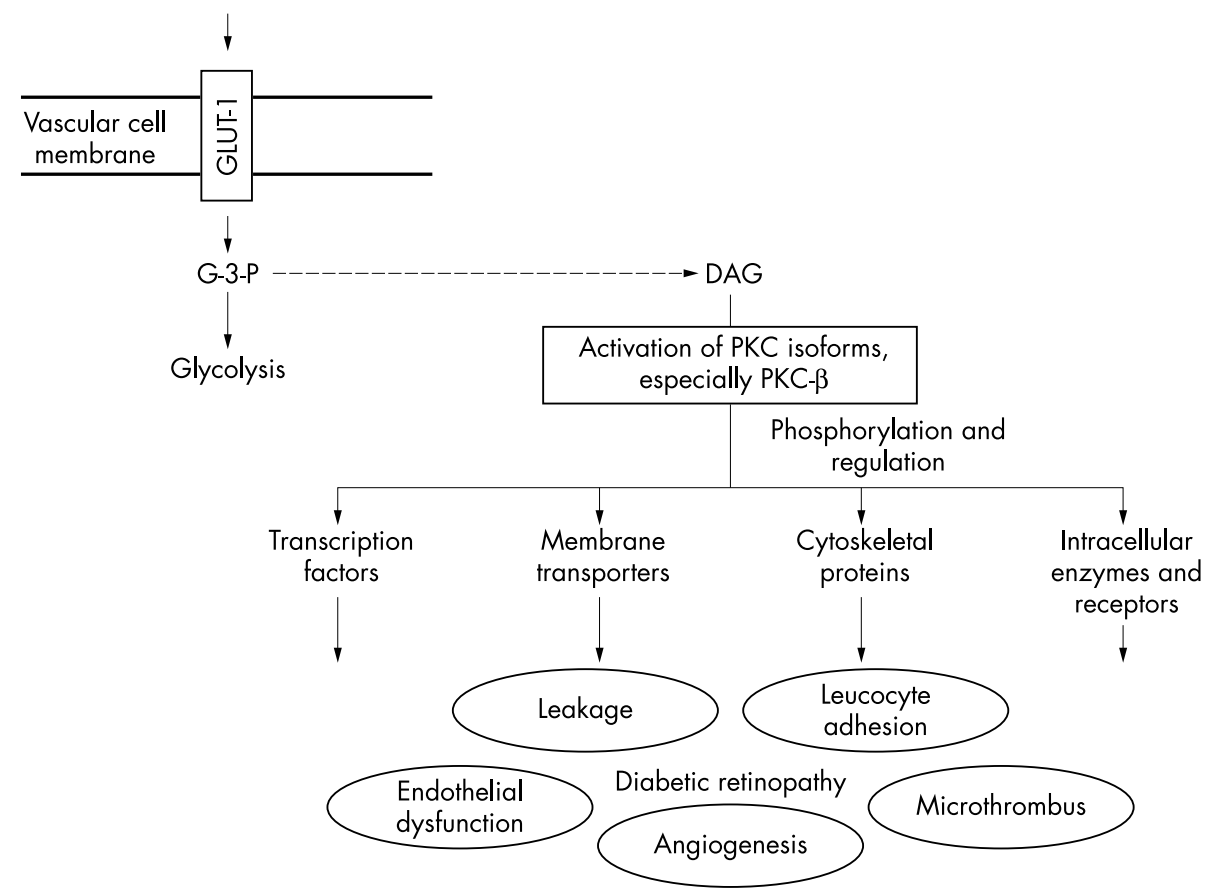

Figure 1 Under hyperglycaemic conditions glucose enters vascular and retinal cells via the GLUT 1 transporter and is metabolised by glycolysis.

Accumulation of an intermediate in glycolysis, glyceraldehyde-3-phosphate (G-3-P), leads to de novo synthesis of DAG, which in turn activates one or more PKC isozymes, especially but not exclusively PKC- $\beta$. PKC mediated phosphorylation of transcription factors, cytoskeletal proteins, enzymes and transporters in turn affects many of the pathophysiological features of diabetic retinopathy.

plasma glucose concentrations in both diabetic and nondiabetic subjects. ${ }^{17}$

\section{PKC involvement in VEGF production and VEGF action} Vascular endothelial growth factor (VEGF, also known as vascular permeability factor) is a cytokine with powerful angiogenic and mitogenic actions which has a major role in retinal leakage (that is, macular oedema) and neovascularisation. ${ }^{18}$ Ocular levels of VEGF correlate with new vessel formation in patients with diabetes, ${ }^{19}$ and intravitreal administration of neutralising chimeric proteins attenuates the angiogenic response to VEGF in experimental models. ${ }^{20}$ VEGF binds with high affinity to the vascular endothelium via two receptors: fms-like tyrosine kinase 1 (flt-1) (also known as VEGF-Rl) and fetal liver kinase 1 (flk-1) (also known as VEGF-R2). VEGF-R1 is expressed on both endothelial and non-endothelial cell types, whereas VEGF$\mathrm{R} 2$ is expressed only on endothelial cells and especially in the retinal microcirculation. ${ }^{21}$ VEGF binding to either receptor type triggers phosphoinositol hydrolysis and release of DAG, which in turn leads to activation of PKC- $\alpha, \beta$, and $\delta .{ }^{22}$ Thus, the permeability and angiogenic responses to VEGF-for example, induced by hypoxia, ${ }^{9}$ are dependent upon selective activation of classic and novel PKC isozymes, but PKC- $\beta$ seems to be especially important in VEGF signalling. For example, the angiogenic response to retinal ischaemia is

Table 1 PKC is a family of isoenzymes, divided into three groups according to cofactor $\left(\mathrm{Ca}^{2+}\right)$ and phospholipid (PL) requirements

\begin{tabular}{llll}
\hline Group $\mathbf{A}$ & Group B & Group C \\
\cline { 1 - 1 } Classic (cPKCs) & Novel (nPKCs) & Atypical (aPKCs) \\
\cline { 1 - 2 } $\mathrm{Ca}^{2+}$ and PL dependent & $\mathrm{Ca}^{2+}$ independent & $\mathrm{Ca}^{2+}$ and PL \\
$\alpha$ & and PL dependent & independent \\
$\beta_{1}$ & $\delta$ & 1 \\
$\beta_{\| I}$ & $\epsilon$ & $\lambda^{*}$ \\
$\gamma$ & $\eta$ & $\zeta$ \\
& $\mu$ & \\
\hline
\end{tabular}

*PKC- $\lambda$ and PKC- -1 may be species homologues. increased in mice overexpressing the PKC- $\beta_{\mathrm{II}}$ isoform, and the mitogenic action of VEGF was increased twofold in retinal endothelial cells overexpressing the PKC- $\beta_{\mathrm{I}}$ and $\beta_{\mathrm{II}}$ isoforms. ${ }^{23}$ In addition, use of a specific PKC- $\beta$ inhibitor confirms that this isozyme is particularly important in VEGF mediated responses, including the effects of VEGF on the blood-retinal barrier leading to macular oedema formation. ${ }^{24}$

Formation of VEGF is also at least partly PKC dependent. Several studies have shown that VEGF gene transcriptionfor example, in response to hypoxia and/or hyperglycaemia, is dependent upon PKC activation. ${ }^{79}$ Furthermore, other pathways involved in diabetic microangiopathy-for example, release of adhesion molecules, TGF- $\beta$, and fibronectin accumulation, are also regulated at the transcriptional level by individual PKCs, often in conjunction with MAP kinase and/or NF- $\kappa$ B. ${ }^{25-27}$ Thus, several disease mechanisms which upregulate the expression of genes and harmful gene products seem to do so, at least in part, via PKC activation.

\section{Leucocyte adhesion and PKC activation}

There is increasing evidence that leucocytes are involved in the pathogenesis of diabetic retinopathy. ${ }^{28}$ Increased leucocyte adhesion, in part secondary to upregulation of ICAM-1, neutrophil integrins, ${ }^{29}$ and other proinflammatory molecules, leads to retinal capillary leakage, occlusion, and microthrombosis. $^{30-32}$ PKC isoforms are highly expressed in circulating white cells and platelets, and PKC enzyme activity in circulating monocytes has been correlated with plasma glucose concentrations. ${ }^{17}$ Thus, leucocyte adhesion to retinal endothelial cells involves several PKC dependent pathways. ${ }^{25}$ In patients with diabetes, increased levels of shed adhesion molecules in the serum, particularly E -selectin and VCAM-1, correlate with the severity of retinopathy, ${ }^{33}$ and these shed adhesion molecules are angiogenic in their own right.

\section{Reduced $\mathrm{Na}^{+}-\mathrm{K}^{+}$and $\mathrm{Ca}^{2+}$-ATPase activity}

Glucose induced increases in arachidonic acid release, prostaglandin- $\mathrm{E}_{2}$ production and inhibition of $\mathrm{Na}^{+}-\mathrm{K}^{+}$and $\mathrm{Ca}^{2+}$-ATPase activities are mediated by PKC activation, especially PKC- $\beta .^{34}{ }^{35}$ Reduction in membrane transporter activity contributes to early functional and structural changes associated with retinopathy, in particular changes in micro- 
circulatory flow, capillary pressure, and intercellular communication. ${ }^{35}$

\section{DEVELOPMENT AND CHARACTERISATION OF ISOFORM SELECTIVE INHIBITORS OF PKC- $\beta$}

Because PKC plays such a fundamental part in signal transduction in different tissues, it seemed likely that broad spectrum inhibitors of PKC isozymes would be associated with multiorgan dysfunction and toxicity in humans. First and second generation PKC inhibitors developed for experimental use-for example, staurosporin and the isoquinolinesulphonamides (for example, GF 109203X), were not even specific for $\mathrm{PKC}$, but as the biochemical and functional profiles of individual PKC isoforms became clearer there has been renewed interest in the therapeutic opportunities for isoform selective blockade of PKC activation-for example, using antisense oligonucleotides ${ }^{10}$ or macrocyclic bis-indolylmaleimide compounds. ${ }^{36}$ In 1996, the chemical characterisation and in vivo pharmacological profile of a highly selective and orally active PKC- $\beta$ inhibitor, ruboxistaurin mesylate (LY333531), was reported in Science. ${ }^{37}$ Ruboxistaurin has considerable selectivity and reversibility for inhibiting PKC- $\beta_{\text {I }}$ and PKC $-\beta_{\text {II }}$ with IC $_{50}$ values (drug concentration required to inhibit isoenzyme activity by $50 \%$ ) of around $5 \mathrm{nM}$ (>100 times lower than the $\mathrm{IC}_{50}$ values for other PKC isoforms and other kinases). ${ }^{37}$ The experimental profile of ruboxistaurin and related analogues with PKC- $\beta$ inhibitory activity have been evaluated in a range of experimental models related to diabetic retinopathy and other microvascular complications (for example, peripheral neuropathy).

\section{Effects of ruboxistaurin on retinal blood flow}

A reduction in retinal blood flow is an early feature of diabetic retinopathy, ${ }^{38}$ probably caused by imbalances between two important vasoactive molecules: increased endothelin-1 (ET-1) production and ET-1 responsiveness ${ }^{39}$ combined with reduced nitric oxide (NO) availability, in part due to reduced NO synthase production. ${ }^{40}$ These abnormalities in retinal haemodynamics have been attributed, at least in part, to increased retinal PKC activity, ${ }^{14}$ and diabetes induced upregulation of ET- 1 is mediated by PKC- $\beta_{\mathrm{I}}{ }^{41}$ Furthermore, administration of ruboxistaurin decreased retinal PKC activity (fig 2) and restored $\mathrm{Na}^{+}-\mathrm{K}^{+}$-ATPase activity in diabetic rats ${ }^{35}$ (fig 3), and attenuated the decline in retinal blood flow ${ }^{36}$ (fig 4). Early phase clinical studies have also confirmed the favourable effects of ruboxistaurin on normalising retinal blood flow in patients with type 1 and type 2 diabetes. ${ }^{42}$

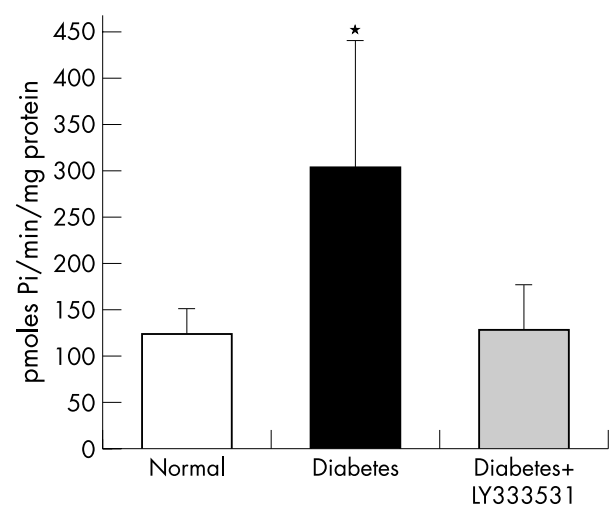

Figure 2 PKC activity in freshly isolated retinal microvessels from normal and diabetic rats, and animals treated with ruboxistaurin. Thus, most of the increase in PKC activity in retinal vessels in diabetes seems to

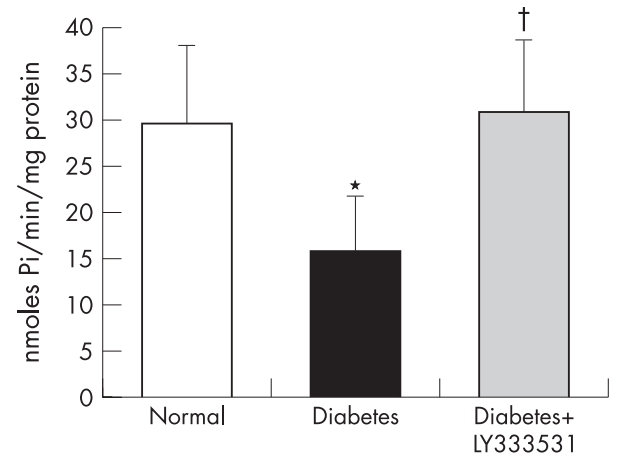

Figure $3 \mathrm{Na}^{+}-\mathrm{K}^{+}$-ATPase activity in retinal microvessels of normal and diabetic rats, and animals treated with ruboxistaurin. The PKC- $\beta$ inhibitor restores the diabetes related reduction in $\mathrm{Na}^{+}-\mathrm{K}^{+}$-ATPase activity. Reproduced from Kowluru et al. ${ }^{35}$

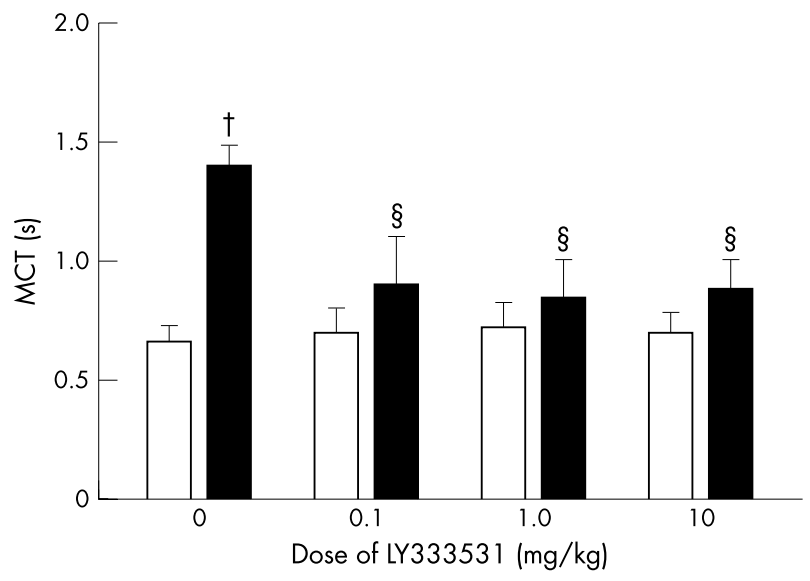

Figure 4 Retinal mean circulation time (MCT, seconds) in STZ diabetic rats (solid bars) and non-diabetic rats (open bars) after 2 weeks of treatment with vehicle (dose zero) or different doses of ruboxistaurin $(0.1-10 \mathrm{mg} / \mathrm{kg} /$ day). Diabetes is associated with a reduction in retinal blood flow (increased MCT), which is ameliorated by the PKC- $\beta$ inhibitor. Importantly, ruboxistaurin has no effect on MCT in nondiabetic animals. Reproduced from Ishii et al. ${ }^{37}$

\section{Effects of PKC- $\beta$ inhibition on retinal permeability and neovascularisation}

There is considerable interest in the pathophysiological role of PKC- $\beta$ activation on pathways of VEGF formation and VEGF action in the retinal endothelium. Ruboxistaurin reduces VEGF induced retinal permeability, ${ }^{24}$ and systemic administration in a pig model of branch retinal vein occlusion effectively attenuated new vessel formation on the retina and optic nerve. ${ }^{43}$ Furthermore, PKC- $\beta$ inhibition with ruboxistaurin reduced the mitogenic response to VEGF, in contrast with PKC- $\alpha$ inhibition (using an antisense oligonucleotide). ${ }^{22}$ Thus, activation of PKC- $\beta$ seems to be an essential step in VEGF mediated endothelial cell migration and replication (early steps in angiogenesis). A study in rats showed that intravitreal VEGF administration increases retinal vascular permeability in conjunction with activation of PKC- $\alpha, \beta_{\mathrm{II}}$, and $\delta .{ }^{24}$ Thus, PKC- $\beta$ is important but not the sole PKC isozyme involved in these unwanted pathways.

Transgenic mice overexpressing PKC- $\beta_{\mathrm{II}}$ show an increased angiogenic response to retinal ischaemia, and in knockout mice lacking the PKC- $\beta$ isoform there was a significant decrease in retinal neovascularisation. ${ }^{23}$ Furthermore, the mitogenic action of VEGF was twofold higher in retinal endothelial cells of mice overexpressing the PKC- $\beta$ isoform, ${ }^{23}$ 
confirming the important role of PKC- $\beta$ in mediating angiogenic responses in diabetic retinopathy.

\section{Effects of PKC- $\beta$ inhibition on leucocyte adhesion}

Oral administration of ruboxistaurin reduces diabetes induced leucocyte entrapment in the retinal microcirculation. $^{44}$

\section{CLINICAL TRIALS OF PKC- $\beta$ INHIBITION: TRANSLATIONAL RESEARCH IN PRACTICE; FROM "PROOF OF CONCEPT" TO "HARD END POINT" STUDIES}

Randomised controlled clinical trials (RCTs) in diabetic retinopathy first began in the 1970s and 1980s, initially to evaluate the effects of laser photocoagulation ${ }^{45} 46$ but more recently to study the retinal protection conferred by medical interventions on glucose and blood pressure control. ${ }^{47} 48$ These studies have helped define the natural history of diabetic retinopathy, but at the same time highlighted the wide intersubject and intrasubject variability in retinal appearances and clinical progression. In particular, it is clear that intersubject variability exists in the relation between retinal appearances, however scored or assessed, and visual outcome, even though new vessels and macular oedema formation confer a serious threat to vision.

The clinical development of ruboxistaurin began with phase I tolerability and pharmacokinetic studies in healthy volunteers, ${ }^{49}{ }^{50}$ followed by phase II efficacy studies in patients with diabetes. ${ }^{51}$ In those with type 1 or type 2 diabetes and minimal or no evidence of diabetic retinopathy, ruboxistaurin increased retinal blood flow in a dose dependent manner, maximal after $32 \mathrm{mg}$ daily for 1 month. ${ }^{51}$ Having confirmed the basic safety and tolerability of ruboxistaurin, and demonstrated that it has pharmacodynamic activity on retinal blood flow, large international RCTs were initiated to evaluate the safety and efficacy of the treatment in larger patient groups during longer term administration (2-4 years). The PKC-Diabetic Retinopathy Study (DRS) and the PKC-Diabetic Macular Edema (DME) Study were international randomised, placebo controlled trials designed to evaluate whether oral treatment with ruboxistaurin will delay progression in patients with moderate to severe non-proliferative diabetic retinopathy at baseline, including progression from non-clinically significant to clinically significant macular oedema (CSMO). ${ }^{52}$ Results for approximately 1000 patients followed for an average of 3646 months should be announced soon.

Since there have been no previous drugs with similar disease modifying potential in the eye, the design and execution of a phase III clinical development programme for ruboxistaurin in diabetic retinopathy raised a number of challenges and uncertainties with regard to patient selection, study design, and choice of trial end points. This review considers some of the more general aspects of such a clinical development programme, and discusses the desirable features and potential difficulties for evaluating an oral agent in this clinical setting. It is immediately clear that translational research, in practice, is not entirely straightforward.

Is a PKC- $\beta$ inhibitor likely to be introduced into clinical practice as first line (mono) therapy or as add-on therapy? How this decision impacts upon trial design Although background medical therapy for glucose and blood pressure reduction applies to nearly all patients with diabetic retinopathy, in terms of primary therapies for the eye this important question has an immediate impact on the design of phase III clinical trials and licensing applications for a new drug. In general, it is often prudent for safety reasons to introduce new drug therapies of any sort as second line, add-on treatments, at least initially, in which case clinical trials of a PKC- $\beta$ inhibitor should include (or at least not exclude) patients receiving laser photocoagulation. Furthermore, clinical trials should be deliberately pragmatic - that is, randomising a wide range of patients to active drug or placebo as add-on treatment to "usual care." This has the added advantage for international studies because it allows for regional differences in "usual care"for example, differences in relation to choice of antidiabetic or cardiovascular therapies and differences in criteria or techniques for administering laser treatment. Including patients who are receiving laser treatment has further advantages, because only $50 \%$ of moderate visual loss from macular oedema is prevented by photocoagulation therapy. ${ }^{53}$ Thus, there is ample opportunity for drugs used as add-on treatments to laser to improve visual outcome.

Of course, for understandable commercial reasons the pharmaceutical industry tends to focus on achieving a licence that supports a monotherapy, primary prevention indication, instead of positioning the drug more conservatively, at least initially, for use as add-on treatment in a targeted high risk (but numerically smaller) subgroup of patients who may have fewer life years of treatment opportunity remaining.

\section{Limitations of clinical trials based on surrogate end points}

Historically, new medical treatments for a range of cardiovascular diseases were licensed by regulatory authorities both in Europe and the United States based on phase III clinical trials with surrogate end points. For example, it has previously been sufficient to show that a drug lowers blood pressure or cholesterol levels, rather than demonstrating that the drug reduces the incidence of stroke or myocardial infarction (MI). More recently, however, this approach has been questioned, not least by healthcare providers who need to assess the clinical and cost effectiveness of new technologies, and the pharmaceutical industry has responded by designing and conducting multicentre trials with hard end points-for example, mortality for cardiovascular interventions. ${ }^{55}$ This experience has demonstrated that studies with more robust and meaningful end points are clinically and commercially feasible if powered and designed to recruit high risk patients with a high incidence of end points despite best "usual care." For such trials to accomplish their objectives over a 2-5 year period, with realistically modest numbers of participants, the entry criteria need to identify those patients at highest risk of serious unwanted outcomes of the disease-for example, fatal or non-fatal MI, but experience over recent years has shown that trials of this kind are perfectly feasible, albeit expensive to conduct.

In RCTs of diabetic retinopathy, grading of retinal appearances has been incorporated either as primary or secondary end points in several large multicentre studies. ${ }^{2}$ The reference standard for semiquantitative assessment of diabetic retinopathy, based on the ETDRS protocol, ${ }^{56}$ involves grading of seven $30^{\circ}$ stereoscopic images of the retina. Each of seven standard fields are assessed for quality and then compared with sets of standard photographs to derive a measure of severity for each lesion. Some trials, however, have adopted a simplified procedure-for example, four stereo fields were used in the UKPDS study, ${ }^{46}$ and two $45^{\circ}$ non-stereoscopic fields were used for the EURODIAB and EUCLID studies..$^{57} \mathrm{~A}$ score is then assigned to each eye, ranging from 10 (no retinopathy) to 85 (advanced proliferative retinopathy), and the grades for both eyes are combined into a scale of steps. ${ }^{2}$ Progression of diabetic retinopathy in the UKPDS was defined as a difference of at least two steps on this scale, compared with baseline, 
whereas in the DCCT sustained progression of retinopathy was defined as at least three steps worsening over baseline.

Thus, most RCTs after ETDRS have used surrogate end points-for example, two or three step worsening or changes in microaneurysm count, since the number of microaneurysms has been shown to correlate with retinopathy progression. $^{59}{ }^{60}$ Few, if any, studies (apart from UKPDS) have included hard end points such as blindness or doubling of the visual angle, yet in individual patients there can be a variable and inconsistent relation between ETDRS scores and visual outcome.

\section{Feasibility of hard end point trials with a PKC- $\beta$ inhibitor as add-on therapy to laser photocoagulation in clinically significant macular oedema}

Improving visual outcome is the unavoidable goal in clinical management; progression of diabetic retinopathy and loss of vision still occurs, all too often, despite optimal diabetes care and timely use of laser photocoagulation, especially in patients with macular oedema. In particular, decreased peripheral and night vision often complicate laser treatment, as well as alterations in colour perception. It is our view that, given the experimental data favouring use of ruboxistaurin to ameliorate leakage and ischaemia in macular oedema, further clinical trials should not exclude patients receiving laser treatment. A trial is urgently needed to evaluate ruboxistaurin as add-on therapy to "usual care," which should include patients receiving laser photocoagulation for clinically significant macular oedema, and it is essential that the trial be simple and pragmatic with a primary end point of stabilisation or improvement of visual acuity relative to placebo.

The feasibility and desirability of conducting hard end point trials (that is, visual outcome as the primary end point) in diabetic retinopathy is sometimes questioned. Conducting hard end point trials of primary prevention in a heterogeneous population of patients with moderate but non-sight threatening diabetic retinopathy would be difficult, possibly requiring several thousand participants and long term follow

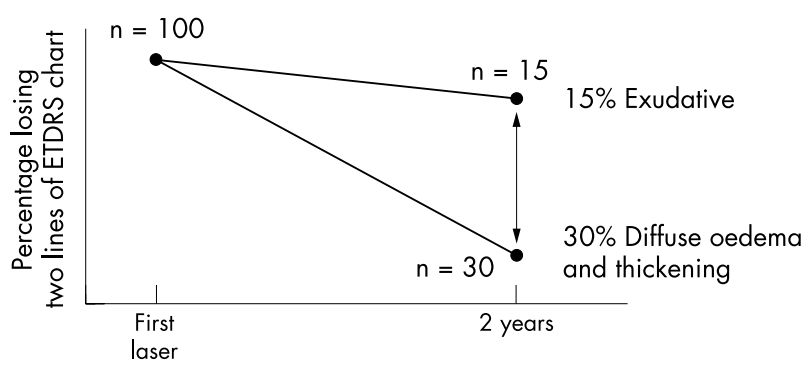

Figure 5 The basis of a proposed clinical trial to evaluate the effectiveness of ruboxistaurin on visual outcome 2 years after initial laser photocoagulation in patients with diabetes and clinically significant macular oedema (CSMO). From previous studies, 15-30\% of patients with CSMO will have lost two lines of ETDRS vision 2 years after first laser therapy. ${ }^{61}$ Patients with exudative maculopathy have a much better visual outcome (approximately 15\% lose two lines after 2 years),

whereas those with diffuse macular oedema and thickening do less well (approximately $30 \%$ lose two lines after 2 years). Assuming the trial is pragmatic and recruits patients with varying degrees of CSMO, we could estimate that around $20 \%$ of patients overall will lose two lines of ETDRS vision 2 years after first laser, despite optimal "usual care." If we then hypothesise that add-on treatment with ruboxistaurin will achieve a $15-20 \%$ risk reduction in the likelihood of losing two lines of vision after 2 years, the study would need sufficient power (80\% likelihood) to detect a difference between $20 \%$ of patients in the control group (laser + placebo) $v 16 \%$ in the treated group (laser + ruboxistaurin) losing two lines of vision after 2 years. On these assumptions and hypotheses, a randomised trial would require approximately 900 patients in each of two treatment arms. up in order to achieve the required number of visual end points to demonstrate a difference between active treatment and placebo. In contrast, among patients with more advanced disease and those most at risk of visual loss despite best "usual care," such a trial is much more feasible (fig 5).

\section{Recognising potential differences in treatment effects on different pathophysiological components of diabetic maculopathy}

It is particularly important that studies should include primary end points that are clearly defined. For instance, diabetic retinopathy is "sight threatening" but reduced vision may be due to a variety of causes-for example, new vessel formation, which constitutes a future risk to visual acuity and is therefore "sight threatening," or diabetic maculopathy which may be sight threatening if it comprises leaky exudates close to the fovea but may actually be sight damaging or sight losing if it is caused by macular thickening or macular ischaemia. It is particularly important in the case of maculopathy that these different entities are not lumped together since the natural history and the risk of visual loss for each macular pathology is different. The outcome measure, CSMO, has been valuable in directing our attention to the macula as a cause of visual loss, and while there was only one treatment available for all forms of maculopathy it was not necessary to separate out each pathological entity. However, now that newer treatments are coming online for the management of maculopathy, it is becoming evident that some of these treatments may be beneficial for some types of macular disease but not others-for example, for macular oedema but not for parafoveal exudate control or macular ischaemia. There is thus a need for better, objective quantitative measurements of these pathologies. Automated computer analysis for each discrete entity may be the way forward but robust systems of analysis are awaited. In the meantime, reliance on primary end point measures such as visual acuity should form the basis of clinical trials, provided it is still possible to undertake prespecified subgroup analyses in the context of the different types of pathology at the macula.

\section{CONCLUSION}

Hyperglycaemia induced de novo synthesis of DAG in vascular cells leads to selective activation of PKC isozymes, especially but not exclusively PKC- $\beta$, which in turn phosphorylates proteins involved in endothelial function (permeability and vasodilator functions), smooth muscle cell growth and contractility, and neovascularisation. Excessive PKC activation therefore underlies the triad of microvascular ischaemia, leakage, and angiogenesis in diabetic retinopathy. Ruboxistaurin is an orally active, $\beta$ specific PKC inhibitor which seems to be well tolerated and normalises retinal blood flow in diabetic patients with retinopathy. The design and execution of larger phase III trials in this ground breaking area raises complex and challenging difficulties. In particular, trials should be pragmatic; PKC- $\beta$ inhibition may be used as add-on therapy; and the entry criteria should include easily identifiable patients at high risk of sight threatening retinal complications, and the primary end points for such trials should include visual outcome. This implies that in future clinical trials patients with clinically significant macular oedema requiring laser photocoagulation should not be excluded, since a significant proportion still experience failing vision despite best usual care.

\footnotetext{
Authors' affiliations

R Donnelly, I Idris, School of Medical and Surgical Sciences, University of Nottingham, UK
} 
J V Forrester, Department of Ophthalmology, University of Aberdeen, UK

Conflict of interest: RD and JF have received consultancy fees from Eli Lilly \& Co for attending meetings of a UK scientific advisory board for ruboxistaurin. II was supported in part through an unrestricted educational grant from Eli Lilly \& Co to the University of Nottingham.

\section{REFERENCES}

1 Zhang LY, Krzentowski G, Albert A, et al. Risk of developing retinopathy in Diabetes Control and Complications Trial type 1 diabetic patients with good or poor metabolic control. Diabetes Care 2001;24:1275-9.

2 Porta M, Bandello F. Diabetic retinopathy: an update. Diabetologia 2002;45:1617-34.

3 Idris I, Gray S, Donnelly R. Protein kinase C activation: isozyme-specific effects on metabolism and cardiovascular complications in diabetes. Diabetologia 2001;44:659-73.

4 Nishizuka $Y$. The molecular heterogeneity of protein kinase $C$ and its implications for cellular regulation. Nature 1988;334:661-5.

5 Huang Q, Yuan Y. Interaction of PKC and NOS in signal transduction of microvascular hyperpermeability. Am J Physiol 1997;273:H2442-51.

6 Park J-Y, Takahara N, Gabriele A, et al. Induction of endothelin-1 expression by glucose: an effect of protein kinase $\mathrm{C}$ activation. Diabetes 2000:49:1239-48.

7 Williams B, Gallacher B, Patel H, et al. Glucose induced protein kinase C activation regulates vascular permeability factor (VEGF) mRNA expression and peptide production by human vascular smooth muscle cells in vitro. Diabetes 1997:46:1497-503.

8 Pomero $F$, Allione A, Beltramo $E$, et al. Effects of protein kinase $C$ inhibition and activation on proliferation and apoptosis of bovine retinal pericytes. Diabetologia 2003;46:416-19.

9 Aiello LP, Northrup J, Keył BA, et al. Hypoxic regulation of vascular endothelial growth factor in retinal cells. Arch Ophthalmol 1995; 113:1538-44.

10 Liao D-F, Monia B, Dean N, et al. Protein kinase $C-\zeta$ mediates angiotensin II activation of ERK1/2 in vascular smooth muscle cells. J Biol Chem 1997:272:6146-50.

11 Housey GM, O'Brien CA, Johnson MD, et al. Isolation of cDNA clones encoding protein kinase $C$ : evidence for a protein kinase $C$-related gene family. Proc Natl Acad Sci USA 1987;84:1065-9.

12 Hug $H$, Sarre TF. Protein kinase $C$ isoenzymes: divergence in signal transduction? Biochem J 1993;291:329-43.

13 Craven PA, Davidson PM, DeRubertis FR. Increase in diacylglycerol mass in isolated glomeruli by glucose from de novo synthesis of glycerolipids. Diabetes 1990:39:667-74.

14 Shiba T, Inoguchi T, Sportsman JR, et al. Correlation of diacylglycerol and protein kinase $\mathrm{C}$ activity in rat retina to retinal circulation. Am J Physiol 1993;265:E783-93.

15 Inoguchi T, Battan R, Handler E, et al. Preferential elevation of protein kinase $\mathrm{C}$ isoform-beta II and diacylglycerol levels in the aorta and heart of diabetic rats: differential reversibility to glycemic control by islet cell transplantation. Proc Natl Acad Sci USA 1992;89:11059-63.

16 Knott RM, Keenan FE, Muckersie E, et al. Glucose-dependent decreased DNA synthesis in bovine retinal endothelial cells is mediated by protein kinase Ciota. Biochem Soc Trans 1998;26:S260.

17 Ceolotto G, Gallo A, Miola M, et al. Protein kinase C activity is acutely regulated by plasma glucose concentration in human monocytes in vivo. Diabetes 1999:48:1316-22.

18 Ozaki H, hayashi H, Vinores SA, et al. Intravitreal sustained release of VEGF causes retinal neovascularization in rabbits and breakdown of the bloodretinal barrier in rabbits and primates. Exp Eye Res 1997:64:505-17.

19 Aiello LP, Avery A, Arrigg PG, et al. Vascular endothelial growth factor in ocular fluids of patients with diabetic retinopathy and other retinal disorders. N Engl J Med 1994;331:1480-7.

20 Aiello LP, Pierce EA, Foley ED, et al. Suppression of retinal neovascularization in vivo by inhibition of vascular endothelial growth factor (VEGF) using soluble VEGF-receptor chimeric proteins. Proc Nat Acad Sci USA 1995;92:10457-61

21 Jakeman LB, Winer J, Bennett GL, et al. Binding sites for vascular endothelia growth factor are localized on endothelial cells in adult rat tissues. J Clin Invest 1992;89:244-53

22 Xia $\mathrm{P}$, Aiello $\mathrm{L}$, Ishii $\mathrm{H}$, et al. Characterization of vascular endothelial growth factor's effect on the activation of protein kinase $C$, its isoforms and endothelia cell growth. J Clin Invest 1996:98:2018-26.

23 Suzama K, Takahara N, Suzuma l, et al. Characterization of protein kinase C beta isoform's action on retinoblastoma protein phosphorylation, vascular endothelial growth factor-induced endothelial cell proliferation and retinal neovascularization. Proc Natl Acad Sci USA 2002;99:721-6.

24 Aiello LP, Bursell SE, Clermont A, et al. Vascular endothelial growth factorinduced retinal permeability is mediated by protein kinase $C$ in vivo and suppressed by an orally effective beta-isoform-selective inhibitor. Diabetes 1997;46: 1473-80.

25 Park CW, Kim JH, Lee JW, et al. High glucose-induced intercellular adhesion molecule-1 (ICAM-1) expression through an osmotic effect in rat mesangial cells is PKC-NF- $\mathrm{KB}$-dependent. Diabetologia 2000;43:1544-53.

26 Studer RK, Craven PA, DeRubertis F. Role of protein kinase $C$ in the mediation of increased fibronectin accumulation by mesangial cells grown in highglucose medium. Diabetes 1993;42:118-26.
27 Koya D, Jirousek MR, Lin Y-W, et al. Characterisation of protein kinase C $\beta$ isoform activation on the gene expression of transforming growth factor- $\beta$ extracellular matrix components, and prostanoids in the glomeruli of diabetic rats. J Clin Invest 1997; 100:115-26.

28 Miyamoto K, Hiroshiba N, Tsujikawa A, et al. In vivo demonstration of increased leukocyte entrapment in retinal microcirculation of diabetic rats. Invest Ophthalmol Vis Sci 1998;39:2190-4.

29 Barouch FC, Miyamoto K, Allport JR, et al. Integrin-mediated neutophil adhesion and retinal leukostasis in diabetes. Invest Ophthalmol Vis Sci 2000;41:1153-8

30 Schroder S, Palinski W, Schmidt-Schonbein GW. Activated monocytes and granulocytes, capillary non-perfusion and neovascularization in diabetes retinopathy. Am J Pathol 1991;139:81-100.

31 Miyamoto K, Khosrof S, Bursell SE, et al. Vascular endothelial growth factor (VEGF)-induced retinal vascular permeability is mediated by intercellular adhesion molecule-1 (ICAM-1). Am J Pathol 2000;56:1733-9.

32 Ishibashi T, Tanaka K, Taniguchi Y. Platelet aggregation and coagulation in the pathogenesis of diabetic retinopathy in rats. Diabetes 1981;30:601-6.

33 Olson JA, Whitelaw CM, McHardy KC, et al. Soluble leucocyte adhesion molercules in diabetic retinopathy stimulate retinal capillary endothelial cell migration. Diabetologia 1997:40:1166-71.

34 Xia P, Kramer RM, King GL. Identification of the mechanism for the inhibition of $\mathrm{Na}$-K-adenosine triphosphatase by hyperglycaemia involving activation of protein kinase $\mathrm{C}$ and cytosolic phospholipase A2. J Clin Invest 1995:96:733-40.

35 Kowluru RA, Jirousek MR, Stramm L, et al. Abnormalities of retinal metabolism in diabetes or experimental galactosaemia versus relationship between protein kinase C and ATPases. Diabetes 1998;47:464-49.

36 Jirousek MR, Gillig JR, Gonzalez CM, et al. (s)-13-[(dimthylamino)methyl]$10,11,14,15$-tetrahydro-4,9:16,21-dimetheno- $1 \mathrm{H}, 13 \mathrm{H}$ dibenzo $[\mathrm{e}, \mathrm{k}]$ pyrrolo $[3,4][1,4,13]$ oxadiazacyclohexadecene-1,3(2H)-dione (LY333531) and related analogues: isozyme selective inhibitors of protein kinase $\mathrm{C}$ beta. J Med Chem 1996;39:2664-71.

37 Ishii $\mathbf{H}$, Jirousek M, Koya $D$, et al. Amelioration of vascular dysfunction in diabetic rats by an oral PKC $\beta$ inhibitor. Science 1996;272:728-31.

38 Bursell SE, Clermont A, Kinsley B, et al. Retinal blood flow changes in patients with IDDM-diabetes mellitus with no diabetic retinopathy: a video fluorescein angiography study. Invest Opthalmol Vis Sci 1996:37:886-97.

39 Takagi C, Bursell SE, Lin Y-W, et al. Regulation of retinal haemodynamics in diabetic rats by increased expression and action of endothelin-1. Invest Ophthalmol Vis Sci 1996;37:2504-518.

40 Chakravarthy $U$, Hayes R, Stitt $A$, et al. Constitutive nitric oxide synthase expression in retinal vascular endothelial cells is suppressed by high glucose and advanced glycation end products. Diabetes 1998;47:945-52.

41 Ronald MA, Rask-Madsen C, Yokota T, et al. Overexpression of endothelin-1 and protein kinase $\mathrm{C}-\mathrm{b} \mathrm{l}$ isoform in vivo mimic abnormal retinal haemodynamics of diabetes. Diabetes 2003;52(Suppl 1):A20.

42 Aiello LP, Bursell SE, Devries T, et al. Protein kinase C- $\beta$-selective inhibitor LY333531 ameliorates abnormal retinal haemodynamics in patients with diabetes. Diabetes 1999:48(Suppl):A19.

43 Danis RP, Bingaman DP, Jirousek $M$, et al. Inhibition of intraocular neovascularization caused by retinal ischaemia in pigs by PKC-beta inhibition with LY333531 Invest Ophthalmol Vis Sci 1998;39:171-9.

44 Nonaka A Kiryu J, Tsujikawa A, et al. PKC-beta inhibitor (LY333531) attenuates leukocyte entrapment in retinal microcirculation of diabetic rats. Invest Ophthalmol Vis Sci 2000;41:2702-6.

45 Diabetic Retinopathy Study Research Group. Photocoagulation treatment of proliferative diabetic retinopathy: the second report of DRS findings. Ophthalmology 1978;85:82-106.

46 Early Treatment Diabetic Retinopathy Study Research Group. Early photocoagulation for diabetic retinopathy. ETDRS report No. 9. Ophthalmology 1991;98:766-85.

47 The Diabetes Control and Complications Trial (DCCT) Research Group. The effect of intensive treatment of diabetes on the development and progression of long-term complications in insulin-dependent diabetes mellitus. New Engl J Med 1993;329:977-86.

48 UKPDS Group. Intensive blood glucose control with sulphonylureas or insulin compared with conventional treatment and risk of complications in patients with type 2 diabetes (UKPDS 33). Lancet 1998;352:837-53.

49 Demolle D, de Suray JM, Onkelinx C. Pharmacokinetics and safety of multiple oral doses of LY333531, a PKC beta inhibitor, in healthy subjects. Clin Pharm Ther 1999:65:189.

50 Demolle D, de Suray JM, Vandenhende F, et al. LY333531 single escalating oral dose study in healthy volunteers. Diabetologia 1998;41(Suppl 1):A354.

51 Aiello LP, Bursell S, Devries T. Protein kinase C beta selective inhibitor LY333531 ameliorates abnormal retinal haemodynamics in patients with diabetes. Diabetes 1999;48:A19.

52 Aiello LP, Davis MD, Sheetz MJ. The PKC Inhibitor Diabetic Retinopathy Study Group. Design, baseline patient characteristics and high prevalence of clinically significant macular edema (CSME) in patients with moderately severe to very severe nonproliferative diabetic retinopathy (NPDR) in the Protein Kinase C Diabetic Retinopathy Study (PKC-DRS). Diabetes 2002;51(Suppl 2):A209.

53 Ferris FL. How effective are treatments for diabetic retinopathy? JAMA 1993;269:1290-1.

54 Ferris FL, Davis MD, Aiello LM. Treatment of diabetic retinopathy. NEngl J Med 1999;341:667-78.

55 Yusuf S, Sleight $\mathrm{P}$, Pogue J, et al. Effects of an angiotensin-converting enzyme inhibitor, ramipril, on cardiovascular events in high-risk patients. The Heart 
Outcomes Prevention Evaluation (HOPE) study investigators. N Engl J Med 2000;342:145-153

56 Early Treatment Diabetic Retinopathy Study Research Group. Fundus photographic risk factors for progression of diabetic retinopathy. ETDRS report No 12. Ophthalmology 1991;98:823-33.

57 Aldington SJ, Kohner EM, Mever S, et al. The EURODIAB IDDM Complications Study Group. Methodology for retinal photography and assessment of diabetic retinopathy: the EURODIAB IDDM Complications Study. Diabetologia 1995;38:437-44.

58 Chaturvedi N, Sjolie AK, Stephenson JM, et al. Effect of lisinopril on progression of retinopathy in normotensive people with type 1 diabetes. The
EUCLID study group. EURODIAB Controlled Trial of Lisinopril in Insulindependent diabetes mellitus. Lancet 1998;35:28-31.

59 Klein R, Mever SM, Moss SE, et al. Retinal microaneurysm counts and 10-yr progression of diabetic retinopathy. Arch Ophthalmol 1995; 113:1386-91.

60 Hellstedt T, Immonen I. Disappearance and formation rates of microaneurysms in early diabetic retinopathy. $\mathrm{Br} J$ Ophthalmol 1996:80:135-9.

61 Lee CM, Olk RJ. Modified grid laser photocoagulation for diffuse diabetic macular oedema. Ophthalmology 1991;98:1594-602.

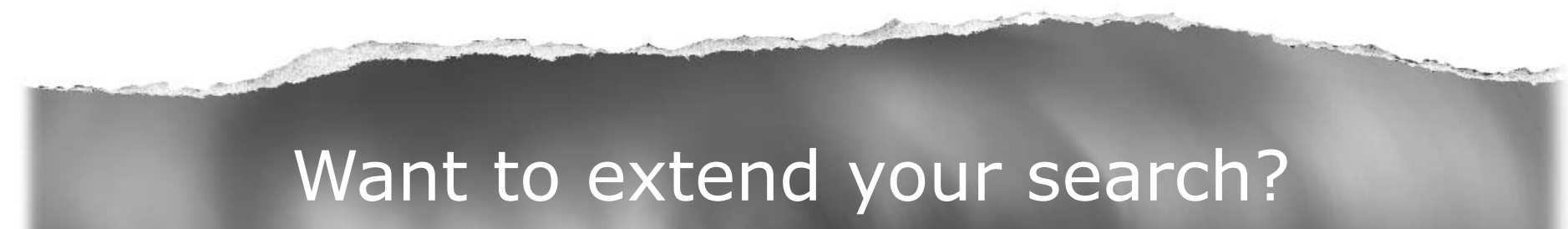

Cross journal searching

Can't find what you're looking for in British Journal of Ophthalmology? Extend your search across 340+ journals. Search restriction options include specific subject areas (eg. clinical medicine, basic research), select specific journals or search all available titles.

www.bjophthalmol.com 